\title{
PERANCANGAN APLIKASI PENGOLAHAN DATA ADMINISTRASI PENDUDUK PADA RUKUN TETANGGA WILAYAH KREO TANGERANG
}

\author{
Adhi Susano ${ }^{1}$, Pujiastuti ${ }^{2}$, Fanisya Alva Mustika ${ }^{3}$ \\ Program Studi Informatika, Universitas Indraprasta PGRI \\ adhi.susano@gmail.com ${ }^{1}$,poetie12@gmail.com², alva.mustika@gmail.com
}

\begin{abstract}
Abstrak
Permasalahan yang ada pada rukun tetangga di wilayah Kreo adalah kegiatan pengolahan dalam surat menyurat dan pendataan penduduk masih di lakukan secara manual., sehingga data yang sudah lama mudah rusak sehingga tidak tersusun dengan rapi dan teratur. Hal ini menyebabkan sulitnya melakukan evaluasi kegiatan yang ada di Rukun Tetangga, demikian juga lambatnya proses pelaporan kegiatan yang dilakukan di ketiga Rukun Tetangga di wilayah tersebut. Tujuan iptek bagi masyarakat ini adalah menghasilkan suatu sistem pengolahan data administrasi pada rukun tetangga (RT) sehingga data-data dalam pelayanan Rukun Tetangga (RT) dapat di laksanakan dan lebih efisien. Dengan adanya aplikasi ini tiap-tiap RT akan dapat lebih efesien dalam pencarian data warganya serta dapat lebih efektif dalam melayanin warganya dalan surat menyurat dan pendataan warga yang ekonominya mampu maupun yang tidak mampu. Hal ini nantinya akan mempermudah pekerjaan petugas sekretariat RW, meningkatkan keterampilan penggunaan teknologi bagi staff rukun tetangga dan dihasilkan data yang lengkap serta pelaporan yang tepat waktu. Selain itu merangsang tiap-tiap RT untuk melakukan inovasi-inovasi yang bermanfaat bagi masyarakat.
\end{abstract}

Kata Kunci : Administrasi, Rukun Tetangga, Penduduk, Aplikasi.

\begin{abstract}
Manual correspondence and community data collection are problems facing by the Neighbourhood Units in Kreo, resulting in the old data collected are easily damaged and are not neatly and tidily arranged. This poses difficulty in evaluating and reporting the existing activities carried out in the three Neighbourhood Units in the region. The aim of this training in science and technology for society is to produce an administrative data processing system in the Neighbourhood Unit (RT) so that the collected data can be more efficiently used during Neighbourhood Unit service. The use of this application may help each Neighbourhood Unit to search data of its community more efficiently and to serve its community more effectively, especially in correspondence and data collection of rich and poor communities. Further, this will facilitate the work of officials in the Community Units $(R W)$, improve the Neighborhood Unit staff's skill at technology, produce complete data, do reporting timely and encourage each Neighbourhood Unit to develop innovations beneficial to the community.
\end{abstract}

Keywords : Administration, Neighbourhood Unit, Citizen, Applicaion.

\section{PENDAHULUAN}

Dengan perkembangan teknologi informasi dan komunikasi yang merambah ke semua bidang, baik disadari maupun tidak disadari, kita telah mendapatkan berbagai kemudahan dari dukungan teknologi tersebut. Tuntutan dari dalam hati nurani tentang kemudahan tersebut juga selalu meningkat pada semua kalangan masyarakat, termasuk kemudahan dan efisiensi dalam menyelesaikan pekerjaan. Hal ini akan memicu para petugas/staff dan warga masyarakat untuk mencari dan mencoba hal-hal dari apa saja yang dapat meningkatkan kinerja dan efektifitas pekerjaan tersebut serta hasil yang diperoleh. Kebutuhan akan komunikasi dan informasi dalam sebuah organisasi atau instansi mutlak diperlukan. Semakin menuntut untuk adanya sistem yang cepat, mudah, efektif dan efisien.

Permasalahan yang ada pada rukun tetangga di wilayah Kreo adalah kegiatan 
pengolahan dalam surat menyurat dan pendataan penduduk masih di lakukan secara manual., sehingga data yang sudah lama mudah rusak sehingga tidak tersusun dengan rapi dan teratur. Hal ini menyebabkan sulitnya melakukan evaluasi kegiatan yang ada di Rukun Tetangga, demikian juga lambatnya proses pelaporan kegiatan yang dilakukan di ketiga Rukun Tetangga di wilayah tersebut.

Berdasarkan dari permasalahan tersebut, maka ada beberapa solusi yang ditawarkan diantaranya masalah yang lebih spesifik agar pemberian pelayanan dan pemberian informasi yang akan didapat oleh warga masyarakat dapat dimanfaatkan secara maksimal. Pembatasan perancangan sistem yang akan dibuat adalah sebagai berikut :

a. Pelayanan pembuatan surat - surat keterangan untuk warga.

b. Pemberian informasi kepada warga masyarakat.

c. Pendataan penduduk tidak mampu dan yang mampu.

d. Pembuatan laporan yang efektif dan efisien.

Dalam referensi [1] menyebutkan bahwa pelayanan adalah setiap tindakan atau kegiatan yang dapat ditawarkan oleh suatu pihak kepada pihak lain, yang pada dasarnya tidak berwujud dan tidak mengakibatkan kepemilikan apapun.

Pada referensi [2] menyatakan bahwa "Dua faktor utama yang mempengaruhi kualitas pelayanan, yakni pelayanan yang diharapkan (expected service) dan pelayanan yang dirasakan/dipersepsikan (perceived service). Apabila pelayanan yang dirasakan sesuai dengan pelayanan yang diharapkan, maka kualitas layanan bersangkutan akan dipersepsikan baik atau positif. Jika pelayanan yang dirasakan melebihi pelayanan yang diharapkan, maka kualitas pelayanan dipersepsikan sebagai kualitas ideal. Sebaliknya apabila perceived service lebih buruk dibandingkan pelayanan yang diharapkan, maka kualitas jasa dipersepsikan negative atau buruk. Oleh sebab itu, baik tidaknya kualitas jasa tergantung pada kemampuan penyedia jasa dalam memenuhi harapan pelanggannya secara konsisten.

Berdasarkan definisi-definisi tersebut di atas dapat disimpulkan bahwa kualitas pelayanan adalah tingkat keunggulan pelayanan yang dapat memenuhi keinginan konsumen/pelanggan yang diberikan oleh suatu organisasi. Agar pelayanan memiliki kualitas dan memberikan kepuasan kepada pelanggan, maka perusahaan harus memperhatikan berbagai dimensi yang dapat menciptakan dan meningkatkan kualitas pelayanan.

Dalam hal ini teknologi informasi dapat digunakan untuk melakukan otomatisasi semua proses kerja atau pelayanan yang baik untuk kebutuhan eksternal maupun internal. Sistem komputerisasi pada sistem pemerintahan sangat dibutuhkan untuk mempermudah sebuah pelayanan dan pemberian informasi didalam melakukan suatu proses pelayanan masyarakat. Salah satu kegiatan pelayanan yang selalu dilakukan setiap harinya adalah pelayanan pembuatan segala bentuk Surat Keterangan, Surat Pemberitahuan yang diperuntukkan untuk warga yang berisikan Himbauan/informasi, pendataan penduduk yang kurang mampu di wilayah Rukun Tetangga (RT) untuk kondisi saat ini masih dilakukan secara manual.

\section{METODE PENELITIAN}

Langkah-langkah yang dilakukan dalam merancang aplikasi pengolahan data penduduk ini diantaranya adalah:

\section{A. Analisa Kebutuhan}

Analisa kebutuhan berguna untuk mendapatkan data-data yang akan digunakan sebagai masukkan dari suatu sistem dan untuk memperoleh data yang berhubungan dengan kegiatan ini. Proses perancangan aplikasi pengolahan data dimulai dari memahami pengguna. 
Sebelum merancang sebuah sistem kita harus memahami kebutuhan pengguna, apa saja yang pengguna inginkan. Langkah-langkah yang dilakukan pada tahap ini adalah :

1) Menentukan profil pengguna.

2) Menganalisa task-task yang digunakan.

3) Menganalisa data masukkan.

4) Menganalisa proses yang berjalan atau proses yang digunakan.

5) Mengumpulkan kebutuhankebutuhan pengguna.

6) Mencocokan kebutuhan tersebut dengan task.

\section{B. Studi Kepustakaan}

Penulis melakukan studi kepustakaan berdasarkan referensi dan berbagai diskusi pembahasan baik dengan dosen pembimbing maupun dengan orang yang berkompeten pada kasus ini. Studi kepustakaan bertujuan untuk mempelajari dan memahami dasar teori yang berhubungan dengan analisa kebutuhan yang telah dilakukan.

Selain itu, penulis juga melakukan studi dari berbagai media yang berupa diktat, modul, buku-buku, artikel-artikel baik di internet maupun media cetak. Selain itu, penulis juga dapat memperoleh informasi tentang penelitian-penelitian yang dilakukan sebelumnya. Dengan melakukan studi kepustakaan, penulis dapat memanfaatkan semua informasi dan pemikiran-pemikiran yang relevan dengan penelitian ini.

\section{Perancangan Sistem}

Perancangan sistem bertujuan untuk merancang sistem yang akan dibuat agar dapat diimplementasikan dengan kebutuhan pengguna. Langkah-langkah yang dilakukan dalam perancangan aplikasi pengolahan data penduduk ini adalah:

1. Merancang Database
Database digunakan untuk menyimpan data-data yang telah diinput atau dimasukkan.

2. Merancang Antarmuka

Dalam merancang antarmuka ada beberapa tahapan yang harus dilalui, yaitu:

1) Merancang menu utama.

2) Merancang form untuk memasukkan dan menyimpan data.

3. Mengembangkan Antarmuka Dalam melakukan pengembangan terhadap antarmuka hal pertama yang harus kita perhatikan adalah membangun prototype. Membangun prototype adalah cara yang berharga dalam membuat rancangan awal dan membuat demonstrasi maka sangat penting untuk melakukan pengujian kegunaan antarmuka. Dari prototype tersebut, perancang antarmuka dapat mulai membangun antarmuka secara utuh.

Ketika membuat prototype, sangat penting untuk diingat bahwa prototype harus dapat dibuang setelah digunakan (disposable), dimana tujuan dalam membuat prototype adalah untuk mempercepat dan mempermudah dalam memvisualisasikan desain alternatif dan konsep, bukan untuk membangun kode yang akan digunakan sebagai bagian dari produk.

4. Melakukan Validasi terhadap Antarmuka

Evaluasi kegunaan adalah bagian penting dari dari proses pengembangan, untuk mengetahui bagaimana tanggapan pengguna terhadap antarmuka yang telah dibuat. Evaluasi ini akan kita gunakan untuk memperbaiki kekurangan pada antarmuka yang telah terbangun. 


\section{Implementasi dan Pengkodean}

Implementasi atau pengkodean adalah proses menterjemahkan dokumen hasil desain menjadi baris-baris perintah bahasa pemrograman sehingga dapat dimengerti oleh komputer. Semakin baik hasil analisis dan desain yang dilakukan, maka proses pengkodean ini akan lebih mudah dilakukan, tanpa adanya kesalahan dalam proses pengkodean yang dilakukan.

E. Pengujian

Implementasi atau pengkodean adalah proses menterjemahkan dokumen hasil desain menjadi baris-baris perintah bahasa pemrograman sehingga dapat dimengerti oleh komputer. Semakin baik hasil analisis dan desain yang dilakukan, maka proses pengkodean ini akan lebih mudah dilakukan, tanpa adanya kesalahan dalam proses pengkodean yang dilakukan.

\section{F. Mengambil Kesimpulan}

1. Apakah fungsi yang terdapat pada aplikasi pengolahan data penduduk sudah dapat digunakan sesuai dengan apa yang diinginkan pada RT.

2. Apakah aplikasi yang dibuat sudah dapat memenuhi kebutuhan untuk suatu proses aplikasi pengolahan data penduduk pada Rukun Tetangga.

\section{HASIL DAN PEMBAHASAN}

Kebutuhan Sistem :

1. Pelayanan pembuatan surat - surat keterangan untuk warga.

2. Pemberian informasi kepada warga masyarakat

3. Pendataan penduduk tidak mampu dan yang mampu

4. Pembuatan laporan yang efektif dan efisien
Berikut ini adalah gambaran proses sistem pengolahan data administrasi rukun tetangga (RT) :

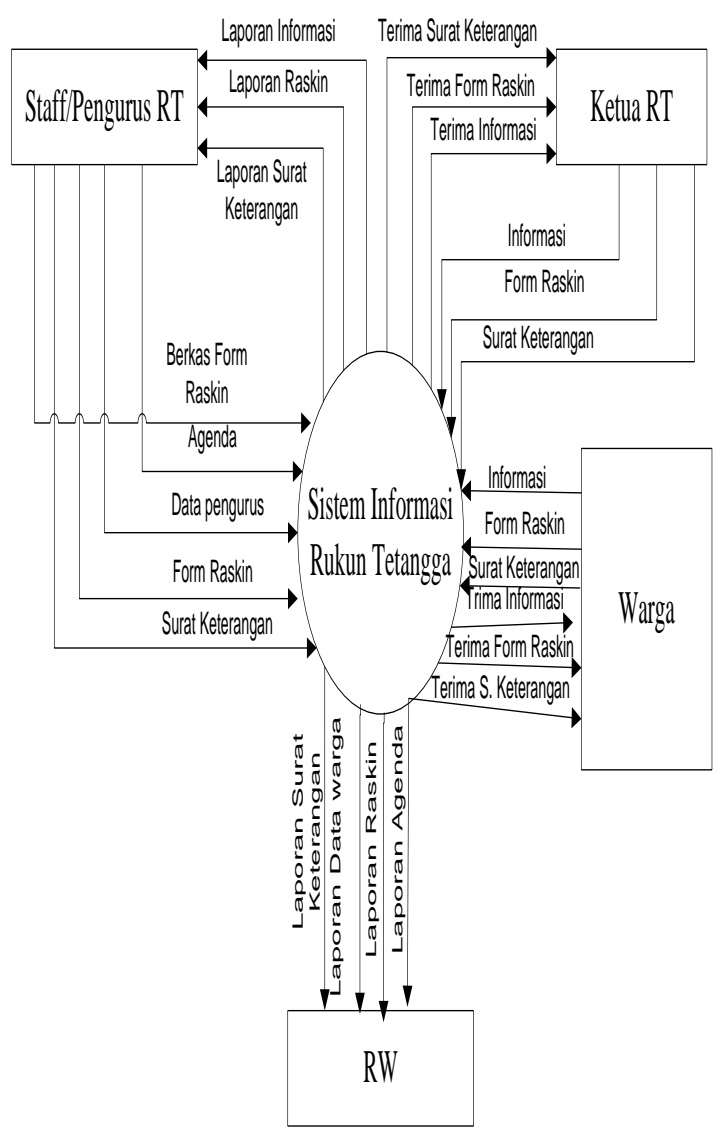

Sumber : Dokumen Pribadi

Gambar 1. Diagram Alir Data

Pengolahan Data Penduduk Rukun Tetangga

Rancangan Layar Menu Utama

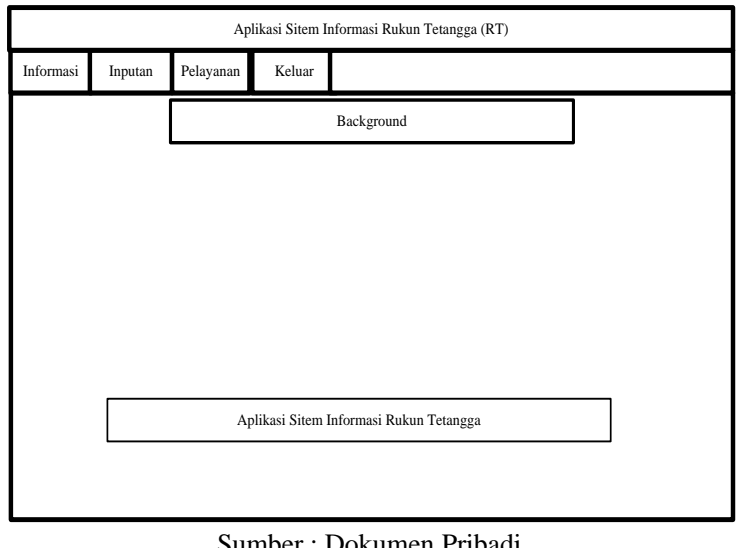

Gambar 2. Rancangan Layar Menu Utama 
Rancangan Layar Agenda Rukun Tetangga (RT)

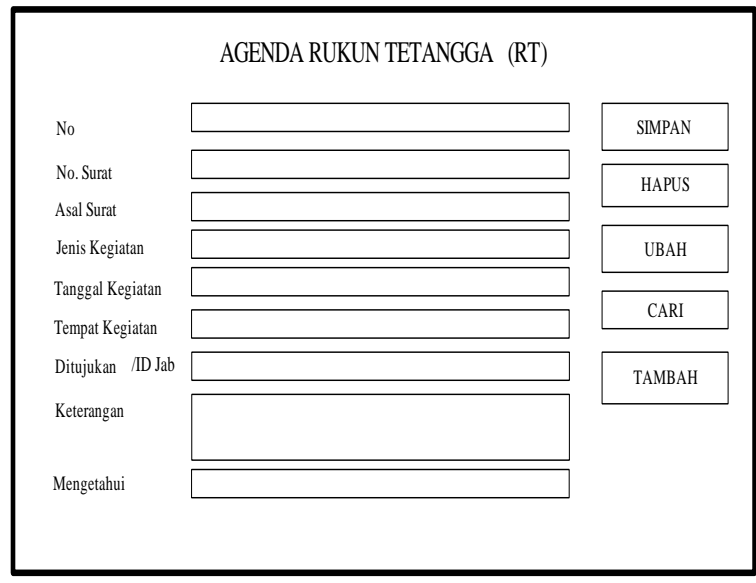

Sumber : Dokumen Pribadi

\section{Gambar 3. Rancangan Layar Agenda \\ Rukun Tetangga}

Rancangan Layar Biodata Staff Rukun Tetangga (RT)

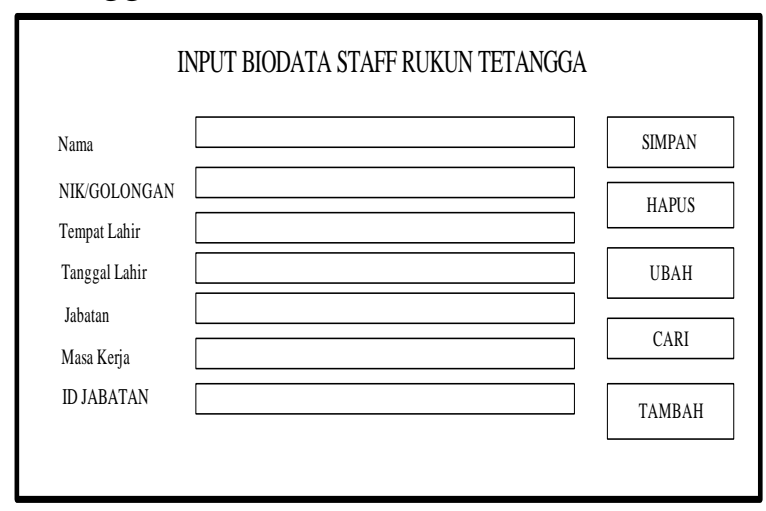

Sumber : Dokumen Pribadi

Gambar 4. Rancangan Layar Biodata Staff RT

Rancangan Layar surat keterangan tidak mampu Rukun Tetangga

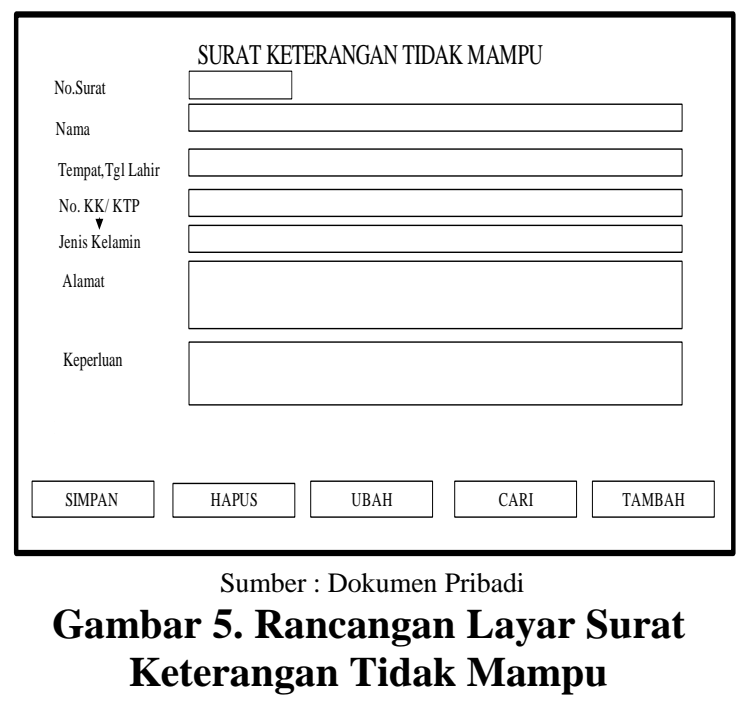

Rancangan Layar Form Raskin

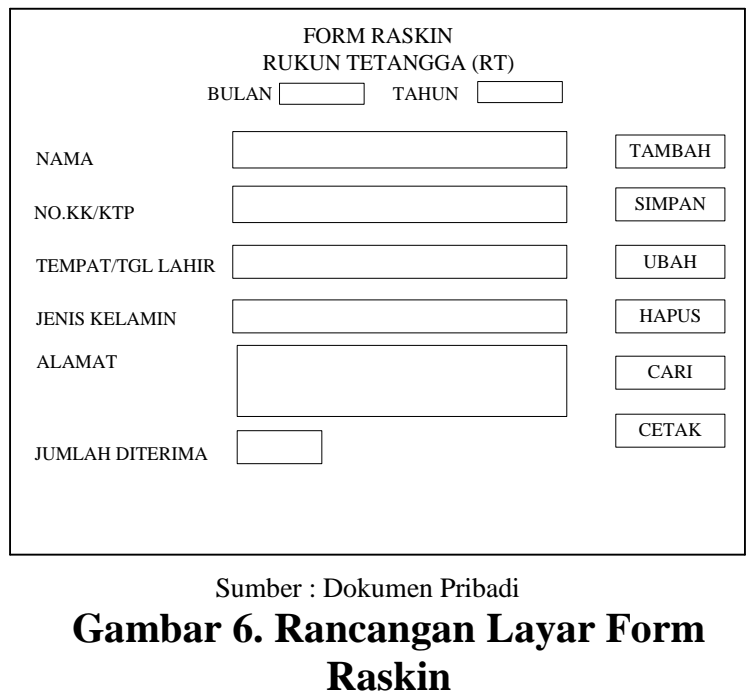

Tampilan Menu Utama

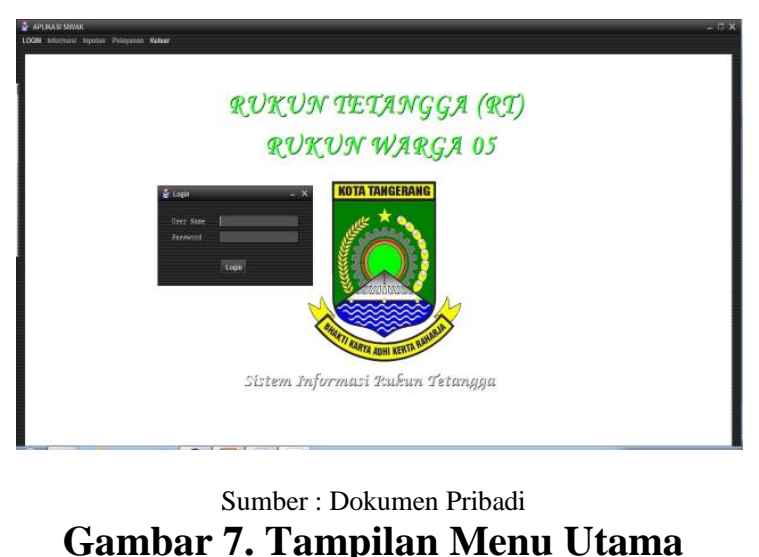

Gambar 7. Tampilan Menu Utama 
Tampilan Agenda Rukun Tetangga

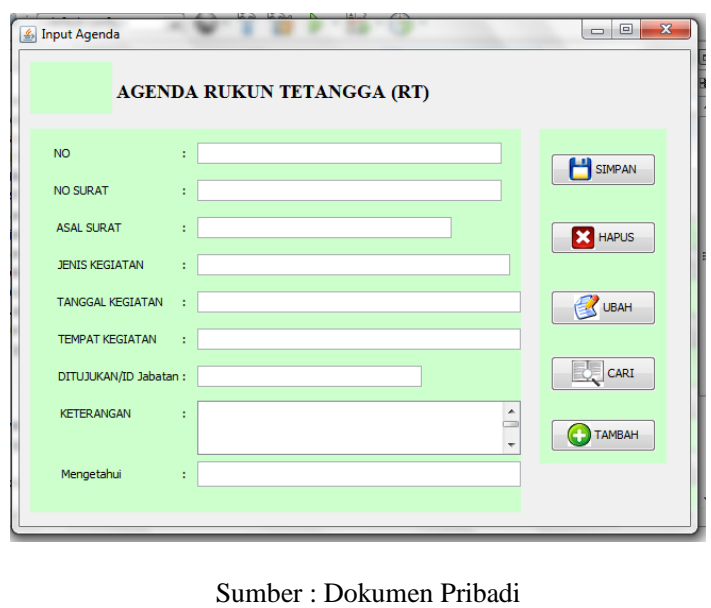

Gambar 8. Tampilan Agenda Rukun Tetangga (RT)

Tampilan Form Raskin

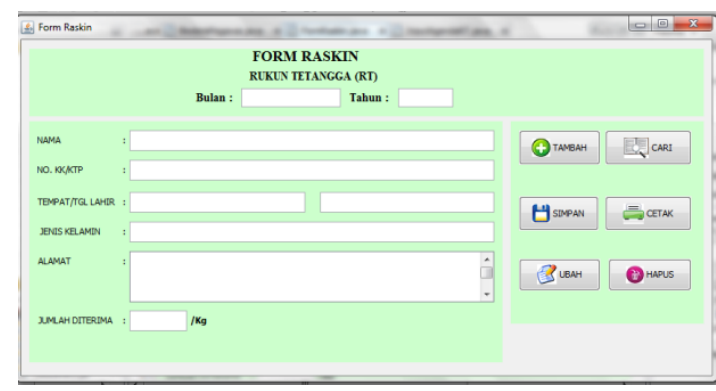

Sumber : Dokumen Pribadi

Gambar 9. Tampilan Form Raskin

Tampilan Biodata Staff

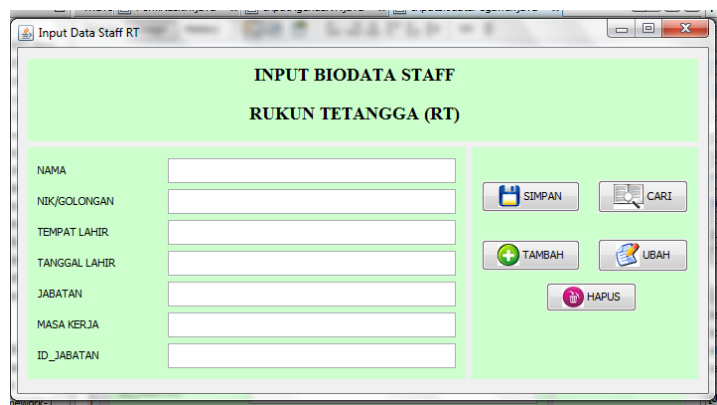

Sumber : Dokumen Pribadi

Gambar 10. Tampilan Biodata Staff
Tampilan Biodata Warga

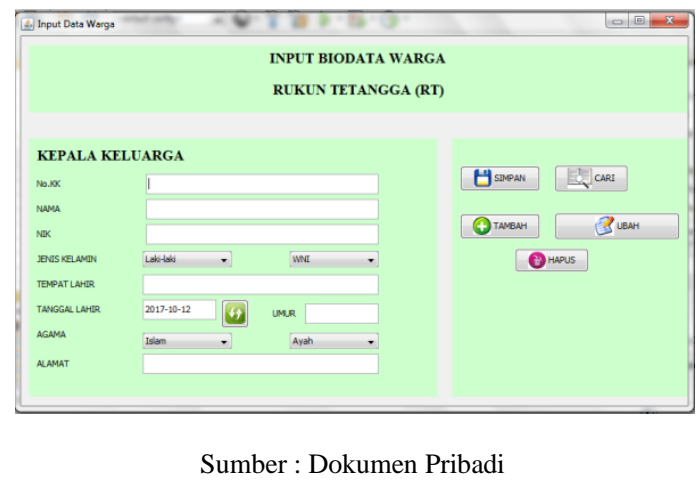

Gambar 11. Tampilan Biodata Warga

Tampilan Surat Keterangan

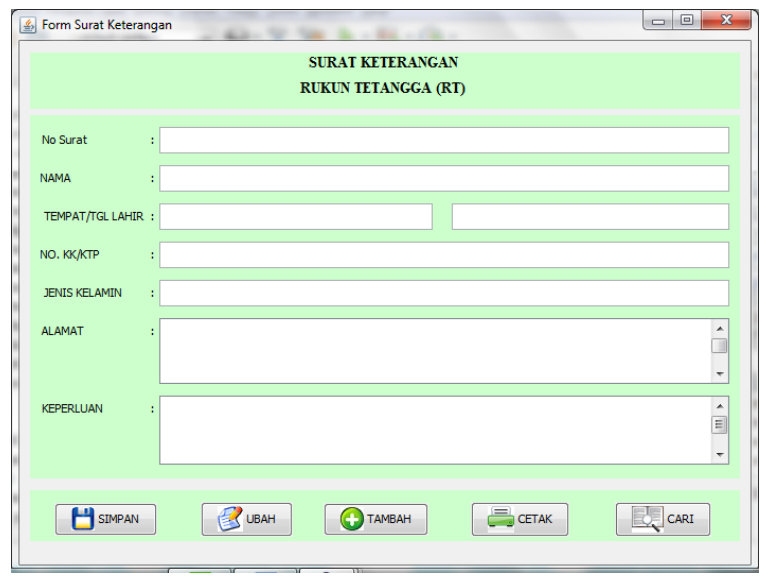

Sumber : Dokumen Pribadi

Gambar 12. Tampilan Surat Keterangan

Tampilan Agenda Kegiatan Warga

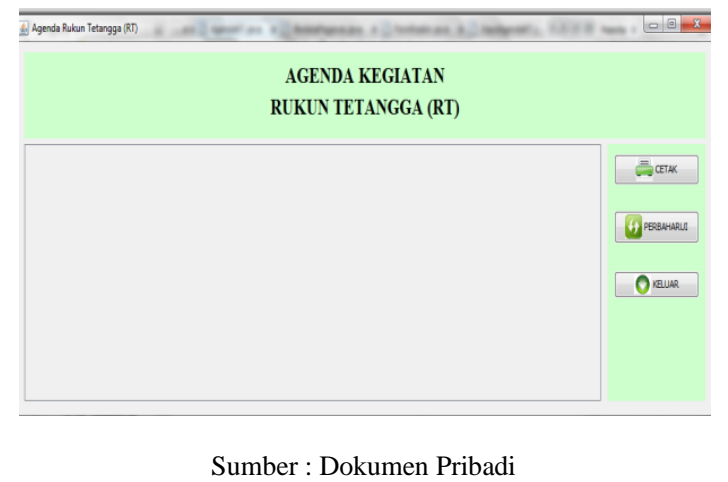

Gambar 13. Tampilan Agenda Kegiatan Warga 
Tampilan Rekap Data Balita

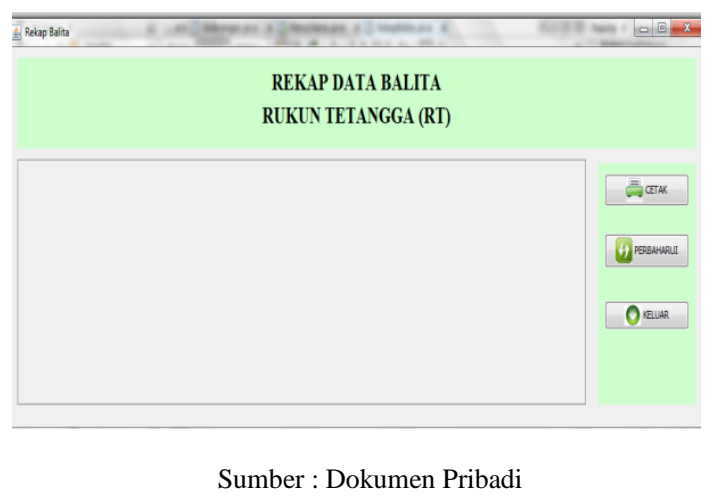

Gambar 14. Tampilan Rekap Data Balita

Tampilan Rekap Data kartu Keluarga

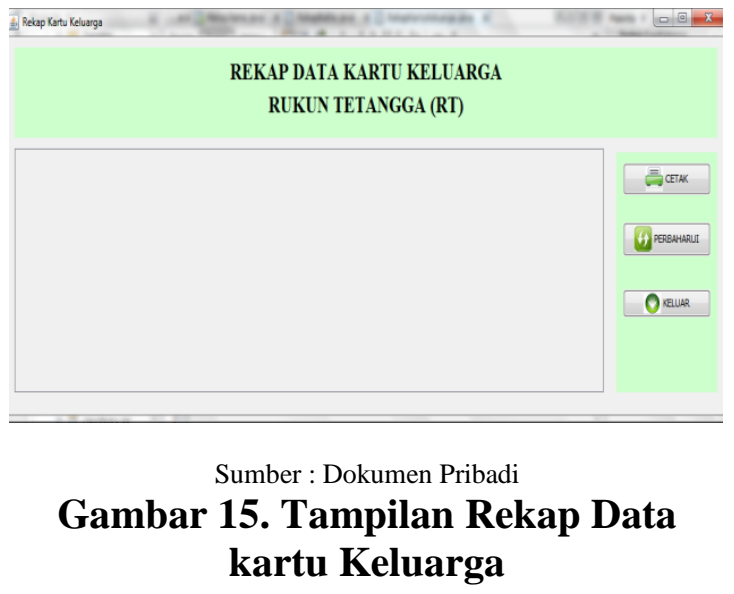

Tampilan Rekap Data Penerima Raskin

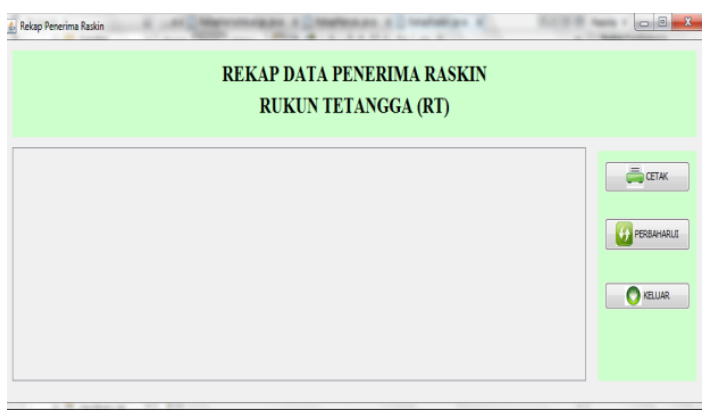

Sumber : Dokumen Pribadi

\section{Gambar 16. Tampilan Rekap Data Penerima Raskin}

Tampilan Rekapitulasi Surat Keterangan

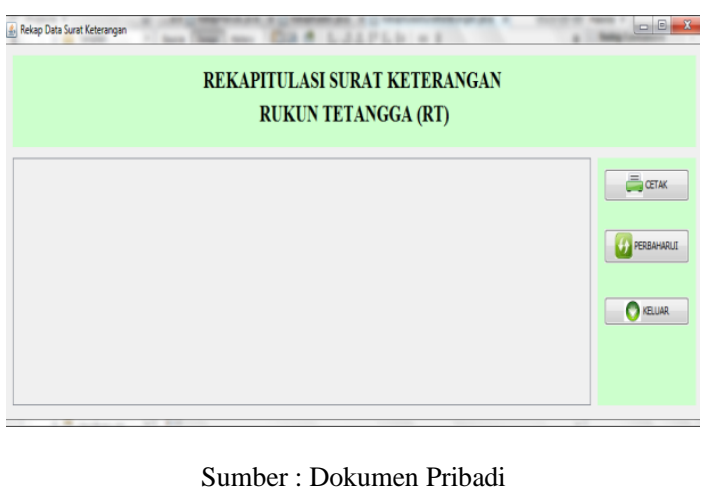

\section{Gambar 17. Tampilan Rekapitulasi Surat Keterangan}

\section{SIMPULAN}

Berdasarkan kegiatan yang telah dilakukan oleh penulis di wilayah Kreo Tangerang, maka dapat disimpulkan sebagai berikut :

1. Aplikasi pengolahan data penduduk dapat mempermudah dalam proses pembuatan surat-surat keterangan untuk warga

2. Dengan adanya aplikasi pengolahan data penduduk pendataan menjadi lebih rapi dan teratur sehingga dapat memberikan pelayanan informasi yang lebih baik kepada warga.

3. Dengan adanya aplikasi pengolahan data penduduk proses pembuatan laporan menjadi lebih efektif dan efisien.

Berdasarkan kesimpulan yang telah dikemukakan, maka disarankan dalam pengembangan selanjutnya akan pengembangan sistem aplikasi agar dapat diperoleh kelemahan-kelemahan sistem untuk melakukan perbaikan-perbaikan dalam mengembangkan sistem informasi warga berikutnya. Pengembangan sistem apliaksi pengabdian masyarakat dapat dilakukan dengan menambah beberapa aspek sistem yang ada, misalnya dengan mengelompokan jumlah pelayananpelayanan yang telah diberikan kepada masyarakat. 


\section{UCAPAN TERIMAKASIH}

Apresiasi dan terima kasih kepada Direktorat Riset dan Pengabdian Masyarakat, Dirjen Penguatan Riset dan Pengembangan, Kementerian Riset, Teknologi dan Pendidikan Tinggi yang telah membiayai kegiatan Pegabdian kepada Masyarakat Ipteks bagi Masyarakat Tahun 2017 dengan judul: "Perancangan dan Penerapan Aplikasi Sistem Pengolahan Data Administrasi Penduduk Pada Rukun Tetangga Wilayah Rukun Warga 005, Kelurahan Kreo, Larangan - Tangerang". Terima kasih juga kepada Kopertis Wilayah III Jakarta dan Lembaga Penelitian dan Pengabdian Masyarakat
Universitas Indraprasta PGRI yang telah membantu kegiatan penelitian ini melalui Kontrak Penelitian 0487/K3/KM/PPM/2017 Tanggal 24 Mei 2017 dan Surat Perjanjian/Kontrak Penelitian UNINDRA Nomor : 0620/SKP.PPM/LPPM/UNINDRA/VI/201 7, Tanggal 05 Juni 2017.

\section{DAFTAR PUSTAKA}

[1] Fajar Laksana. Manajemen Pemasaran. Yogyakarta : Graha Ilmu. 2008.

[2] Tjiptono, Fandy dan Chandra, Gregorius. Manajemen Kualitas Jasa. Yogyakarta : ANDI. 2005. 